\title{
Preliminary investigations toward nighttime aerosol optical depth retrievals from the VIIRS Day/Night Band
}

\author{
R. S. Johnson ${ }^{1}$, J. Zhang ${ }^{1}$, E. J. Hyer ${ }^{2}$, S. D. Miller ${ }^{3}$, and J. S. Reid ${ }^{2}$ \\ ${ }^{1}$ Department of Atmospheric Sciences, University of North Dakota, Grand Forks, ND, USA \\ ${ }^{2}$ Marine Meteorology Division, Naval Research Laboratory, Monterey, CA, USA \\ ${ }^{3}$ Cooperative Institute for Research in the Atmosphere, Colorado State University, Fort Collins, CO, USA \\ Correspondence to: R. S. Johnson (johran@bethel.edu)
}

Received: 22 December 2012 - Published in Atmos. Meas. Tech. Discuss.: 17 January 2013

Revised: 17 April 2013 - Accepted: 17 April 2013 - Published: 14 May 2013

\begin{abstract}
A great need exists for reliable nighttime aerosol products at high spatial and temporal resolution. In this concept demonstration study, using Visible/Infrared Imager/Radiometer Suite (VIIRS) Day/Night Band (DNB) observations on the Suomi National Polar-orbiting Partnership (NPP) satellite, a new method is proposed for retrieving nighttime aerosol optical depth $(\tau)$ using the contrast between regions with and without artificial surface lights. Evaluation of the retrieved $\tau$ values against daytime AERONET data from before and after the overpass of the VIIRS satellite over the Cape Verde, Grand Forks, and Alta Floresta AERONET stations yields a coefficient of determination $\left(r^{2}\right)$ of 0.71 . This study suggests that the VIIRS DNB has the potential to provide useful nighttime aerosol detection and property retrievals.
\end{abstract}

\section{Introduction}

Recent advances in aerosol climate studies (e.g., Kaufman et al., 2002; Zhang et al., 2005a, b) and aerosol and visibility forecasting (e.g., Zhang et al., 2008a, 2011; Benedetti et al., 2009; Sekiyama et al., 2010) have responded to the growing demand for nighttime aerosol retrievals from satellite observations. For example, by using multisensor aerosol products from the Moderate Resolution Imaging Spectroradiometer (MODIS), the Multi-angle Imaging Spectroradiometer (MISR), and the Cloud Aerosol Lidar with Orthogonal Polarization (CALIOP), Zhang et al. (2011) show improvements in aerosol forecasts using combined 2-D/3-D VAR aerosol assimilation. Their study shows that higher forecast errors, measured by comparing modeled and AERONET aerosol optical depth $(\tau)$ data, occur at the 12 and $36 \mathrm{~h}$ forecast ranges, possibly due in part to a lack of nighttime observations. Similarly, reliable nighttime aerosol measurements would improve our understanding of the complete role of aerosol in the climate feedback system (e.g., Zhang et al., 2008b; Zhang and Christopher, 2003). Even if the efficacy of such a product was not as great as its daytime counterpart, provided the uncertainty is known, there is still a potential benefit for aerosol data assimilation applications (Reid et al., 2011).

Despite the increasing needs for aerosol information, the research community faces difficulty in finding nighttime satellite aerosol products that have wide spatial coverage and are optimized to their applications. For example, whereas the CALIOP lidar measures aerosol vertical distributions during both day and night in great detail, the spatial coverage of these data are limited because the instrument observes only a two-dimensional "curtain" through the atmosphere, with spacing of several hundred kilometers between orbital tracks. Furthermore, large uncertainties exist in converting CALIOP measurements of attenuated backscatter to physical quantities such as aerosol optical depth (e.g., Campbell et al., 2010; Winker et al., 2009). Lee and Sohn (2012) demonstrate the utility of thermal infrared (IR) channels in retrieving nighttime aerosol properties; however, such algorithms are only capable of detecting coarse-mode aerosols, and the performance of these retrieval methods could degrade when dust plumes are near the surface.

Using nighttime observations in the visible/near-infrared spectrum from the Operational Linescan System (OLS), Zhang et al. (2008b) demonstrate the potential of detecting 
aerosol plumes by examining the attenuation of artificial lights at night. However, the results from that study are qualitative as the OLS sensor lacks onboard calibrations. The recently launched Visible/Infrared Imager/Radiometer Suite (VIIRS) on the Suomi National Polar-orbiting Partnership (NPP) satellite also includes a Day/Night Band (DNB) lowlight visible sensor that improves upon the OLS design. Unlike the OLS, the VIIRS DNB is well calibrated (e.g., Lee et al., 2006). In this study we use VIIRS DNB observations to detect and retrieve the properties of nighttime aerosol, using data from regions with and without artificial light emissions.

To use the VIIRS DNB sensor to retrieve nighttime $\tau$ we make several basic assumptions. First, we assume that the emission intensity of artificial light sources can be estimated and that a given artificial (city) light source is relatively stable throughout the study period. These assumptions highlight a need to carefully study the global distribution of artificial light sources and the characteristics of their temporal variations in emission intensity. Fortunately, several previous papers have already initiated this attempt (e.g., Elvidge et al., 1999, 2001), yet much remains for future studies. Second, the method specified in this study obtains total optical depth. However, the method is applied in this study only to cloudfree areas based on VIIRS cloud screening, but additional methods to isolate thin cirrus from aerosol may be required. Third, this method works best on nights without moonlight as moonlight adds additional noise to the retrieval process.

\section{Datasets}

Three VIIRS data products were utilized for the current algorithm: the VIIRS/DNB Sensor Data Record-SDR (SVDNB), the VIIRS/DNB SDR Geolocation Content Summary (GDNBO), and the VIIRS Cloud Cover/Layers Height Data Content Summary (VCCLO). The SVDNB product provided radiance values and quality flag information. The GDNBO product provided the corresponding latitude, longitude, solar zenith angle, lunar zenith angle, moon illumination fraction, and satellite zenith angle data. The summed cloud cover from the VCCLO product was used to filter clouds from the analysis. However, as an additional quality check we have visually inspected every study scene for potential cloud contamination missed by the VCCLO. VIIRS DNB data prior to summer 2012 suffered from gain/offset noise. Thus, no data prior to this time were used for the retrieval method shown in this study.

Sun photometer data from several Aerosol Robotic Network (AERONET) stations were used for validation purposes. Although AERONET data are only collected during the daytime, and this study is focused on nighttime retrievals, there are no other available, reliable nighttime aerosol datasets besides CALIPSO (Cloud-Aerosol Lidar and Infrared Pathfinder Satellite Observations) for validation purposes. CALIPSO can provide nighttime $\tau$, but it was de- cided not use this resource as a validation tool because of the very low frequency of overpasses over a given city and the high uncertainty in the CALIPSO-derived $\tau$ product (Campbell et al., 2012). Stellar and lunar photometers are under development and could be used in the future (e.g., Lanciano and Fiocco, 2007; Berkoff et al., 2011), but they are currently unavailable for this study period. Some extinction-measuring lidars may be usable for our study, but currently we are unaware of any quality-assured datasets available in our areas of interest.

Based on data availability, AERONET observations in closest temporal adjacency (before and after) to the VIIRS nighttime overpass were used for validation. Any before- and after-overpass AERONET data that were spaced more than $24 \mathrm{~h}$ apart from each other were not used in the study. The stations used were the Capo Verde station $\left(16.7^{\circ} \mathrm{N}, 22.9^{\circ} \mathrm{W}\right.$ - for validating retrievals from the city of Espargos on Sal Island), the Grand Forks station $\left(47.9^{\circ} \mathrm{N}, 97.3^{\circ} \mathrm{W}-\right.$ for validating retrievals from light sources near Grand Forks, North Dakota), and the Alta Floresta station $\left(9.9^{\circ} \mathrm{S}, 56.1^{\circ} \mathrm{W}-\right.$ for validating retrievals from the city of Alta Floresta, Brazil). The uncertainty in daytime AERONET $\tau$ values is roughly \pm 0.015 (Schmid et al., 1999; Holben et al., 1998). The cloudscreened level 1.5 AERONET data were used in this study as the level 2 AERONET data are not available for 2012 for the selected AERONET sites. Also, AERONET $\tau$ at $0.675 \mu \mathrm{m}$ was used because the VIIRS DNB has a center wavelength of $0.7 \mu \mathrm{m}$ with full width at half maximum response spectral range of 0.5 to $0.9 \mu \mathrm{m}$ (e.g., Lee et al., 2006). AERONET and VIIRS data from 1 August to 31 October 2012 around Sal Island, from 11 June to 31 July 2012 for the Grand Forks area, and from 1 August to 30 September 2012 for Alta Floresta were used.

Three artificial light sources were chosen to represent dust (Cape Verde), urban-background (Grand Forks), and smoke (Alta Floresta) aerosol cases. These sites range from low and stable aerosol loading at Grand Forks to frequent high aerosol loading at Cape Verde and Alta Floresta. These AERONET sites were chosen to capture a wide range of aerosol patterns for the development of the retrieval discussed in this study. It should be noted that the purpose of this paper is not to develop a fully operational nighttime aerosol retrieval product, but to illustrate a new method of retrieving aerosol optical depth at night. Therefore, only limited study periods were used for the three illustrative test cases in this study.

\section{Methodology}

\subsection{Method for estimating nighttime aerosol optical depth with VIIRS}

Figure 1a shows nighttime VIIRS/DNB imagery of Sal Island on Cape Verde from 8 February 2012 at 03:45 UTC, 


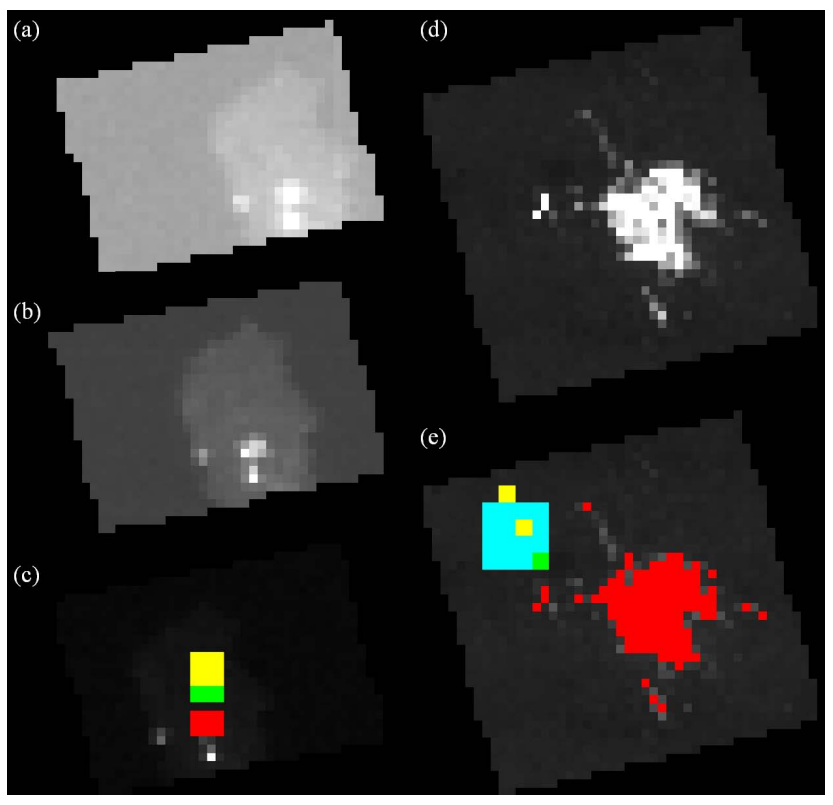

Fig. 1. (a) VIIRS nighttime imagery over Sal Island from the VIIRS Day/Night Band for 8 February 2012. The island is less observable due to the presence of a heavy aerosol plume. (b) Similar to Fig. 1a but for a relatively low aerosol loading night of 9 February 2012. Sal Island can more easily be visually identified from the imagery. (c) Similar to Fig. 1b but 27 October 2012 and with the artificial light sources (manually identified) highlighted in red and selected background pixels highlighted in green. Additional background samples are highlighted in yellow. (d-e) Similar to Fig. 1b-c but for the Grand Forks region on 5 June 2012 and with artificial light sources algorithmically identified. Also, a fourth, enlarged background sample is highlighted in blue. Imagery is radiance $\left(\mathrm{W} \mathrm{cm}^{-2} \mathrm{sr}^{-1}\right)$ multiplied by $10^{10}$ and then plotted in grayscale with values ranging from 0 to 255 , where any value over 255 was set to 255 .

where the AERONET data show $\tau$ of 1.6 on 7 February 2012 at 18:16 UTC and $\tau$ of 0.95 on 8 February 2012 at 10:47 UTC. In comparison, Fig. 1b shows nighttime VIIRS/DNB imagery from 9 February 2012 at 03:26 UTC, where the AERONET data show $\tau$ of 0.96 on 8 February 2012 at 18:08 UTC and 0.28 on 9 February 2012 at 13:32 UTC. The sharp reduction in $\tau$ over the course of the second night indicates a much reduced aerosol loading compared with the first night in Fig. 1a. Both panels ( $a$ and b) in Fig. 1 have similar observing conditions, with lunar zenith angles of $29.2^{\circ}$ for 8 February and $17.0^{\circ}$ for 9 February, and with moon fractions $(100.0=$ full moon) equal to 99.7 for 8 February and 97.9 for 9 February. The satellite zenith angle at the validation site for 8 February is $58.2^{\circ}$ and is $38.0^{\circ}$ for 9 February. In Fig. 1b the land and ocean contrast can be detected, and artificial lights from the city of Espargos on Sal Island can be observed. Compared with the relatively low aerosol loading from Fig. 1b, the land and ocean contrast is almost completely obscured in Fig. 1a when aerosol loading is high. Also, the contrast between artificial city lights and the surrounding background is much reduced in Fig. 1a. Due to the aforementioned gain/offset noise problem, these February data are used only for illustrative purposes.

As suggested from Fig. 1, information from the VIIRS/DNB can be used to obtain nighttime $\tau$ because the contrast between artificial lights and nearby background radiances is reduced in the presence of aerosol plumes and clouds (i.e., via backscattering, absorption, and the horizontal diffusion of scattered artificial light). Utilizing this information a method for retrieving $\tau$ can be developed.

This method is similar to the shadow method developed by Vincent et al. (2006), where the aerosol signals are detected by the difference between observed QuickBird radiance over shadow and non-shadow regions. Following Vincent et al. (2006), the surface upward radiance $\left(I_{\mathrm{S}}\right)$ from the combination of artificial and lunar light sources can be described as

$\pi I_{\mathrm{S}}=r_{\mathrm{s}}\left(\mu_{0} F_{0} e^{-\tau / \mu_{0}}+\mu_{0} F_{0} T\left(\mu_{0}\right)+\pi I_{\mathrm{s}} \bar{r}\right)+\pi I_{\mathrm{a}}$,

where $r_{\mathrm{s}}$ is the surface albedo (assuming a Lambertian surface), $\mu_{0}$ is the cosine of the lunar zenith angle, $F_{0}$ is the incoming irradiance from the moon, $\tau$ is the total optical depth, $T\left(\mu_{0}\right)$ is the diffuse transmittance for moonlight, $\bar{r}$ is the aerosol reflectance, and $I_{\mathrm{a}}$ is the upwelling radiance from artificial light sources. Here we assume that $I_{\mathrm{a}}$ is an isotropic source, although a factor to correct for the angular dependence of $I_{\mathrm{a}}$ is applied in Eq. (7) below. The first and second terms on the right hand side of Eq. (1) represent the direct and diffuse transmission of moonlight. The third term represents the portion of upwelling surface radiance being reflected by the aerosol layer back to (and subsequently by) the surface, and the last term represents the direct emission from any artificial light sources present. By rearranging Eq. (1) we can solve for $I_{\mathrm{S}}$ as shown in Eq. (2).

$I_{\mathrm{S}}=\frac{r_{\mathrm{S}}\left(\mu_{0} F_{0} e^{-\tau / \mu_{0}}+\mu_{0} F_{0} T\left(\mu_{0}\right)\right)+\pi I_{\mathrm{a}}}{\pi\left(1-r_{\mathrm{s}} \bar{r}\right)}$

$I_{\mathrm{S}}$ represents the surface upward radiance, but to compute satellite observed radiance $\left(I_{\mathrm{sat}}\right)$, we need to consider the attenuation by the whole atmospheric column along the lineof-sight and diffuse transmission. Also, the path radiance $\left(I_{\mathrm{p}}\right)$, which represents the observed radiance of energy reflected and scattered by the atmosphere without ground interaction, is included.

$I_{\mathrm{sat}}=I_{\mathrm{s}} e^{-\tau / \mu}+\mu I_{\mathrm{s}} T(\mu)+I_{\mathrm{p}}$

Here $\mu$ is the cosine of the satellite viewing zenith angle, and $\tau$ is the total atmospheric column optical depth. In the visible spectrum, we assume $\tau$ is the optical depth from aerosol layers. However, there will be some inherent uncertainty in this assumption since the DNB response function, full width at half maximum from 0.5 to $0.9 \mu \mathrm{m}$, includes the oxygen Aband. A future study should consider the impact of the oxygen A-band, as well as other absorbing bands such as water vapor, on the proposed algorithm. 
Similarly, for nearby background regions with no artificial light sources, Eq. (2) can be rewritten as

$I^{\prime}{ }_{\mathrm{S}}=\frac{r_{\mathrm{s}}\left(\mu_{0} F_{0} e^{-\tau / \mu_{0}}+\mu_{0} F_{0} T\left(\mu_{0}\right)\right)}{\pi\left(1-r_{\mathrm{s}} \bar{r}\right)}$,

where $I^{\prime}{ }_{\mathrm{s}}$ is the surface upwelling radiance over nearby regions that have no artificial light sources and

$I^{\prime}{ }_{\text {sat }}=I^{\prime}{ }_{\mathrm{s}} e^{-\tau / \mu}+\mu I^{\prime}{ }_{\mathrm{s}} T(\mu)+I_{\mathrm{p}}$,

where $I^{\prime}$ sat is the corresponding VIIRS radiance. By subtracting Eqs. (3) and (5) we get

$I_{\text {sat }}-I^{\prime}{ }_{\text {sat }}=\frac{I_{\mathrm{a}}}{1-r_{\mathrm{s}} \bar{r}}\left(e^{-\tau / \mu}+\mu T(\mu)\right)$.

The first and second terms on the right hand side of Eq. (6) represent the direct and diffuse transmission of artificial light, respectively. For optically thin aerosol layers the diffuse part of the artificial light can be ignored. However, the diffuse part could be significant for optically thick plumes. To account for the diffuse radiance term, we introduce a correction term, $k$, which we assume is the ratio of direct to total (diffuse + direct) artificial light energy. Additionally, $I_{\mathrm{a}}$ needs to be estimated from a cloud-, aerosol-, and moon-free sky. Because $I_{\text {sat }}$ and $I^{\prime}$ sat are by definition observed on a different night than the night from which $I_{\mathrm{a}}$ is derived, the satellite viewing geometry on these two nights could be different. For a single emission source, both $I_{\mathrm{a}}$ and $I_{\mathrm{sat}}$ are functions of satellite viewing zenith angle. Therefore, another correcting factor $C$ (defined in Sect. 3.3) is introduced to account for differences in viewing geometries between the various nights. In future studies some factor like $C$ should also be included to account for differences in water vapor content between various nights. Also, note that $\bar{r} \sim 0.1$ for aerosol optical depth of 1 (e.g., Remer and Kaufman, 1998), so the term $r_{\mathrm{s}} \bar{r}$ can be considered small and eliminated from Eq. (6) for low aerosol loading cases. The $r_{\mathrm{s}} \bar{r}$ term, however, can be significant with thick aerosol plumes. For the study in this paper we assume that the $r_{\mathrm{s}} \bar{r}$ term can be ignored. Finally, we can calculate the aerosol optical depth as

$\tau=-\mu \ln \left(\frac{k\left(I_{\mathrm{sat}}-I_{\mathrm{sat}}^{\prime}\right)}{C I_{\mathrm{a}}}\right)$.

\subsection{Distinguishing artificial lights from the background}

As mentioned in Sect. 3.1, radiance values from both artificial light sources and the background are needed. Therefore, pixels containing direct artificial light emissions from Cape Verde, Grand Forks, and Alta Floresta need to be distinguished from the surrounding background pixels. For Grand Forks, identifying these direct artificial light pixels was accomplished by first focusing in on an area around the city $\left(47.8^{\circ} \mathrm{N}\right.$ to $48.05^{\circ} \mathrm{N}$ and $97.3^{\circ} \mathrm{W}$ to $96.9^{\circ} \mathrm{W}$ ). All radiance values outside of this region were set to 0 . Next the average of all the radiances within this region was calculated. Any pixel whose radiance exceeded 1.5 times the mean radiance, so long as the radiance was at least $0.5 \times 10^{-8} \mathrm{~W} \mathrm{~cm}^{-2} \mathrm{sr}^{-1}$, was identified as a city pixel. A sample of nighttime imagery with and without the identified city pixels, highlighted in red, at Grand Forks can be seen in Fig. 1d and e. A sample of background radiances was also selected each night. For Grand Forks a group of four pixels just north of the airport were manually chosen. An example of these pixels, highlighted in green, is shown in Fig. 1e.

A different approach to choosing city pixels at Cape Verde was required because Espargos was the most consistently viewable city at this location. Thus, to ensure that only pixels from Espargos were selected, a group of 12 pixels containing the city were manually chosen. Of these 12 pixels, the six brightest pixels were selected as the city pixels for Cape Verde. A sample of the Cape Verde imagery with the group of 12 pixels, highlighted in red, can be seen in Fig. 1c. A group of 8 pixels just north of the city of Espargos was manually chosen each night to serve as the background sample. Imagery with these surrounding background pixels, highlighted in green, for Cape Verde is shown in Fig. 1c.

Similarly, Fig. 2a shows the nighttime VIIRS DNB image for Alta Floresta, Brazil, on 3 August 2012. The artificial light source selection method that was used in the Cape Verde case was also applied to Alta Floresta. Each night a block of $20 \times 15$ pixels covering Alta Floresta was chosen. Of these, the fifty brightest pixels, a sample of which is highlighted red in Fig. 2b, were selected to represent Alta Floresta. Similar to Fig. 1 the green pixels highlighted in Fig. $2 b$ represent the background sample that was manually chosen each night.

To determine the impact of choosing one background sample over another on the retrieved $\tau$, two additional supplementary background samples were collected each night at each of the three sites (shown as yellow in Figs. 1c, e, and $2 b)$. The choice for the location of these background samples was random. The motivation for selecting these supplementary background samples is to estimate the possible error introduced to the retrieval by the fact that a selected background sample might not represent the true background.

We first studied the impact of using different background samples that varied in spatial proximity to the city light source. To study the impact of the different background samples on retrieved $\tau$, we looked at the differences in the quantity $I_{\text {sat }}-I^{\prime}$ sat $(\Delta I)$ using the different background samples. It is shown later in Sect. 4.2 that the relative change in $\Delta I$ translates into uncertainty in $\tau$ due to changes in $\Delta I$. This means that by using the same $I_{\mathrm{sat}}$ (city signal) and different $I^{\prime}$ sat values (background signals) that the change in $\Delta I$ translates into the uncertainty in $\tau$ due to changes in the background sample. Thus, we calculated the relative change in $\Delta I$ from using the various background samples each night at each location. For each location we averaged the absolute value of these relative differences over the whole study period. The results are shown in Table 1, and they indicate the 


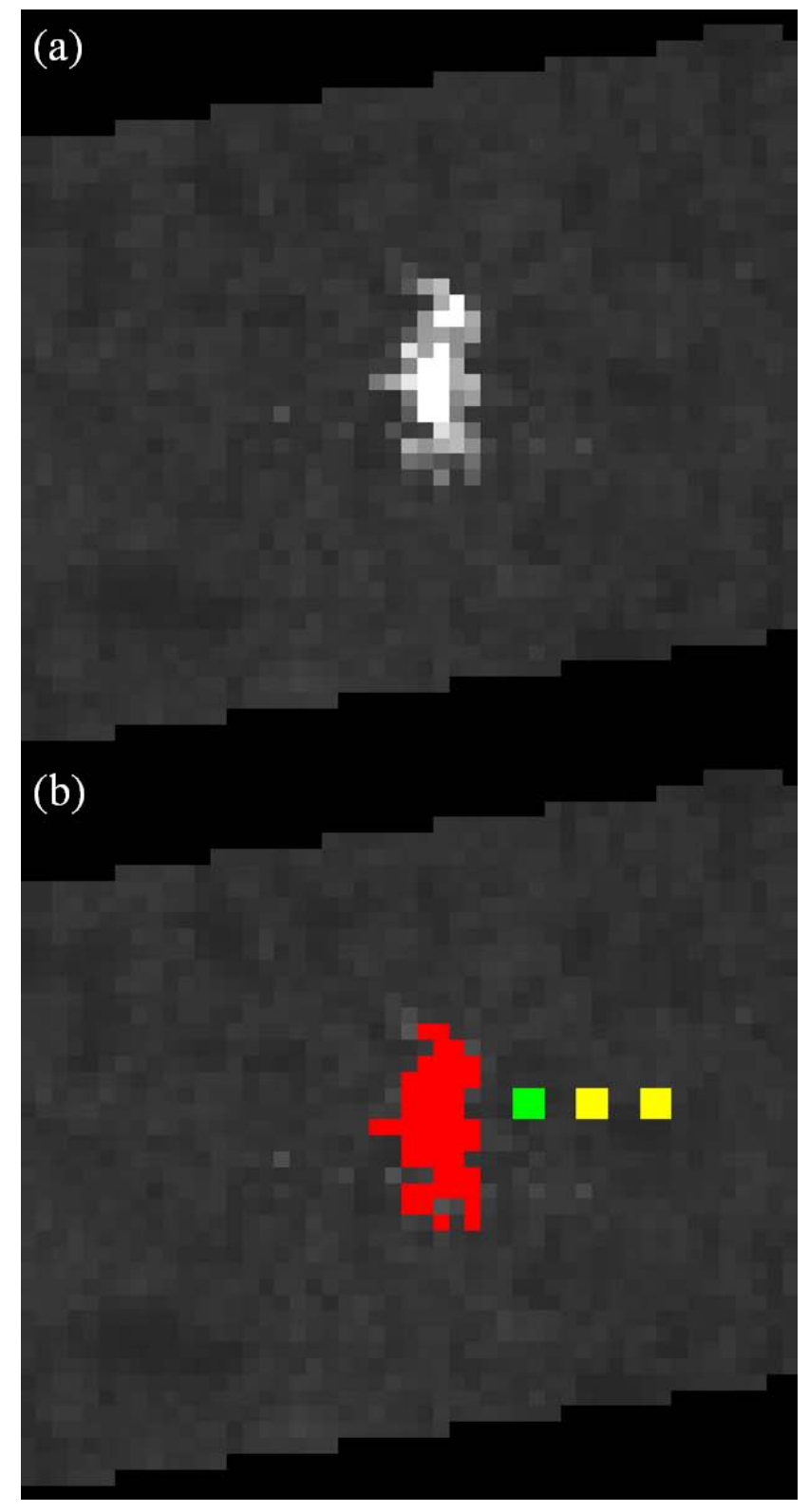

Fig. 2. (a) VIIRS nighttime imagery over Alta Floresta for $3 \mathrm{Au}$ gust 2012. (b) Similar to Fig. 2a with artificial city light sources highlighted in red (collection of the brightest pixels from a manually selected box of pixels covering the city), manually selected background pixels highlighted in green, and additional background pixels highlighted in yellow.

average maximum possible uncertainty in $\tau$ due to varying the background sample as a function of proximity to the city. These values ranged from approximately 0.01 at Grand Forks to 0.03 at Cape Verde. Similar uncertainties in $\tau$ were found for nights with and without moonlight, indicating that moon fraction is less of an issue for estimating $I_{\text {sat }}^{\prime}$ values. The reason why $I^{\prime}{ }_{\text {sat }}$ has such a small impact on the uncertainty of the retrieved $\tau$ is that $\Delta I$, the difference between $I_{\text {sat }}$ and
Table 1. Average maximum uncertainties in retrieved $\tau$ due to different background samples spaced at various distances from the artificial light sources (proximity backgrounds). Also, for Grand Forks, average maximum uncertainty in retrieved $\tau$ due to the use of different-sized background samples (enlarged background).

\begin{tabular}{lrrrr}
\hline & $\begin{array}{r}\text { Cape Verde } \\
\text { Proximity } \\
\text { Backgrounds }\end{array}$ & $\begin{array}{r}\text { Alta Floresta } \\
\text { Proximity } \\
\text { Backgrounds }\end{array}$ & $\begin{array}{r}\text { Grand Forks } \\
\text { Proximity } \\
\text { Backgrounds }\end{array}$ & $\begin{array}{r}\text { Grand Forks } \\
\text { Enlarged } \\
\text { Background }\end{array}$ \\
\hline $\begin{array}{l}\text { Average } \\
\text { maximum } \\
\text { uncertainty }\end{array}$ & 0.03 & 0.02 & 0.01 & 0.01 \\
$\begin{array}{l}\text { in } \tau \text { from } \\
\text { background }\end{array}$ & & & & \\
\hline
\end{tabular}

$I^{\prime}$ sat, is what matters to the optical depth retrieval. $I^{\prime}$ sat constitutes just a small portion of $\Delta I$ since $I_{\text {sat }}$ is typically several times to several magnitudes larger than $I^{\prime}{ }_{\text {sat }}$.

The average maximum uncertainty in $\tau$ of 0.03 was further validated by calculating $\tau$, not corrected for the diffuse transmission of light, with each of the three background values each night. For each city, the average absolute difference between the values of $\tau$ using the supplementary background samples and the primary background sample was indeed less than its respective value shown in Table 1.

Another similar study was performed at Grand Forks, except instead of varying the distance of the background sample from the city source, the size of the background sample was changed. The primary sample size was increased from 4 pixels (shown as green in Fig. 1e) to 64 pixels (shown as blue in Fig. 1e). The average change in retrieved $\tau$ due to this enlargement was less than 0.01 .

\subsection{Derived parameters for the retrieval process}

To derive aerosol optical depth via the method outlined in Eq. (7), values for $I_{\mathrm{a}}, C$, and $k$ are needed. The $I_{\mathrm{a}}$ values are considered to be emissions from artificial lights. As a firstorder approximation, we chose a radiance value for each city from a moonless night where the pair of temporally nearest AERONET $\tau$ values from before and after the VIIRS overpass was at a minimum. For a given artificial light source, the value of $I_{\mathrm{a}}$ was obtained using data from the whole study period. Ideally, $I_{\mathrm{a}}$ values are also functions of viewing geometry, season, time of a day, etc. We leave a more thorough analysis of $I_{\mathrm{a}}$ to a future study. Although we chose $I_{\mathrm{a}}$ as the value of $I_{\text {sat }}$ from the moonless night with the lowest value of estimated nighttime AERONET $\tau$ (using the average of the AERONET values from before and after the VIIRS overpass), we investigated other potential values of $I_{\mathrm{a}}$ based on all of the VIIRS DNB radiance data from moonless nights. By plotting $I_{\mathrm{a}}$ as a function of estimated AERONET $\tau$ and extrapolating to a $\tau$ of 0 , we have estimated the true value of $I_{\mathrm{a}}$ for each city. Then we compared these estimated values of $I_{\mathrm{a}}$ to the values of $I_{\mathrm{a}}$ that were actually used in the study. The percentage difference between the estimated values and the 
actual values that were used in our study are approximately 2, 4, and $2 \%$ at Cape Verde, Grand Forks, and Alta Floresta, respectively. Later in Sect. 4.2 it is shown this corresponds to a maximum uncertainty in $\tau$ of $0.02,0.04$, and 0.02 at Cape Verde, Grand Forks, and Alta Floresta, respectively. At Grand Forks the radiance values were adjusted according to Eq. (8) before extrapolating to a $\tau$ of 0 .

$C$ is the correction factor compensating for the nonhomogeneity property of artificial light intensity that is a function of satellite viewing zenith angle. As mentioned, we use a value of $I_{\text {sat }}$ from a moonless night with low aerosol loading to estimate $I_{\mathrm{a}}$. For a given emission source, however, $I_{\mathrm{a}}$ could be a function of viewing angle. Because of this potential dependence on viewing angle, we need $C$ to account for the differences in viewing geometry between the night when $I_{\mathrm{a}}$ is estimated and the other nights when $I_{\text {sat }}$ is observed. Furthermore, $C$ is also used to correct for an apparent change in $I_{\mathrm{a}}$ due to instrumental variations of radiance based on the satellite viewing zenith angle. Thus, to determine the value of $C$, the relationship between observed radiance and satellite viewing zenith angle needs to be investigated.

In addition to satellite viewing zenith angle, the observed VIIRS DNB radiance will also be affected by other factors such as lunar fraction and lunar zenith angle. However, no adjustments to $I_{\mathrm{a}}$ are needed for these factors for two reasons. First, $I_{\mathrm{a}}$ was chosen from a moonless night when lunar geometry should not affect the observed radiance. Second, any lunar illumination effects should be canceled out each night according to Eq. (7) by taking the difference between the city and the background radiances: $I_{\text {sat }}-I^{\prime}$ sat. Therefore, only the relationship between radiance and satellite viewing zenith angle needs to be investigated.

Figure 3a shows the relationship between observed radiance values $\left(I_{\mathrm{sat}}\right)$ from Grand Forks as a function of the cosine of the satellite viewing zenith angle (CVZA). A highly linear trend with a coefficient of determination $\left(r^{2}\right)$ of 0.84 is found. Also, an approximately $30 \%$ decrease in radiance values are observed as CVZA goes from 0.5 to 1.0. The strong linear trend between radiance values from artificial light sources and CVZA from the Grand Forks study region shows the importance of this relationship and justifies the need for determining the adjustment factor $C$ with regard to CVZA.

It should be noted that the Grand Forks data used in this study is impacted by a known stray-light issue that affects the VIIRS DNB sensor during high-latitude summers. Currently, corrections for the stray-light issue have not been implemented with the VIIRS data. The maximum possible impact of this stray-light issue could only be on the same order of magnitude as the observed background sample values $\left(I^{\prime}\right.$ sat $)$. However, the $I^{\prime}$ sat values are an order of magnitude smaller than the $I_{\text {sat }}$ values shown in Fig. 3a. Furthermore, the difference between the maximum and minimum $I_{\text {sat }}$ values in Fig. 3a is larger than any of the $I^{\prime}$ sat values. Thus, the stray-light issue likely does not fully explain the trend seen
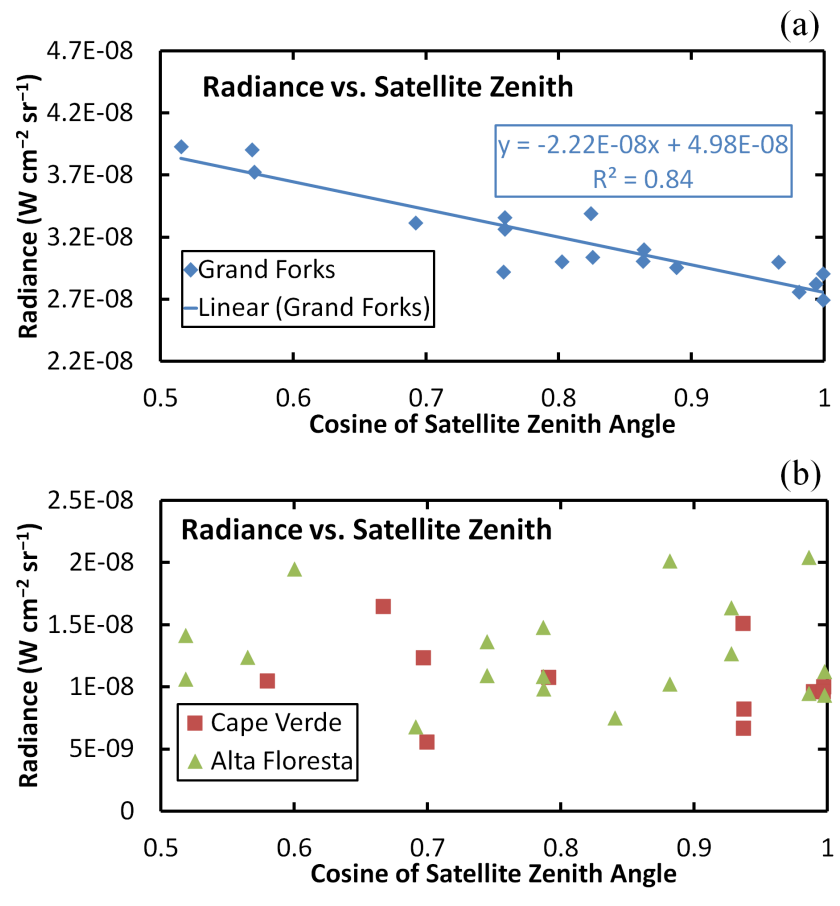

Fig. 3. (a) Radiance versus the cosine of the satellite viewing zenith angle for Grand Forks (blue). (b) Radiance versus the cosine of the satellite viewing zenith angle for Cape Verde (red) and Alta Floresta (green).

in Fig. 3a. The impact of the stray-light issue on this study is further suppressed by the fact that subtracting $I_{\text {sat }}$ and $I^{\prime}$ sat in Eq. (7) should cancel out this effect in the numerator of the equation. As for $I_{\mathrm{a}}$ in the denominator, at Grand Forks its value is an order of magnitude larger than the $I^{\prime}$ sat values, and in Sect. 4.2 we show that this will introduce a maximum possible uncertainty in $\tau$ of $0.05-0.1$ depending on CVZA.

Drawing from the results in Fig. 3a, it is possible to describe the dependence of radiance on the satellite zenith angle. This linear regression relationship can be described as follows:

$I=-2.2249 \times 10^{-8} \times \cos (\theta)+4.9808 \times 10^{-8}$

(Grand Forks),

where $I$ is the estimated radiance in $\mathrm{W} \mathrm{cm}^{-2} \mathrm{sr}^{-1}$ and $\theta$ is the satellite zenith angle. The correction factor $C$ is thus obtained by calculating $I$ with the observing night viewing conditions and dividing it by the $I$ that is calculated with the same viewing conditions as were present during the night when $I_{\mathrm{a}}$ was obtained.

$C=\frac{I\left(\theta_{I_{\text {sat }}}\right)}{I\left(\theta_{I_{\mathrm{a}}}\right)}$

Figure $3 b$ shows the observed radiance values from Cape Verde and Alta Floresta as a function of CVZA. No relationship (near zero correlation) is found between these two 
variables at either location. Therefore, $C$ is set to 1 for the Cape Verde and Alta Floresta cases.

The $k$ value represents the ratio of direct to total artificial light energy observed with the VIIRS DNB. We assume that, for a given atmospheric layer, the upward direct and diffuse transmittances equal the downward direct and diffuse transmittances, per the reciprocity principle. Based on this assumption and using the $6 \mathrm{~S}$ radiative transfer model (Vermote et al., 1997), we estimate the $k$ values. For the purpose of concept demonstration, we used an existing desert aerosol model (Vermote et al., 1997) in the 6S model to represent the Cape Verde cases, an urban aerosol model (Vermote et al., 1997) for the Grand Forks cases, and a biomass burning aerosol model (Vermote et al., 1997) for the Alta Floresta cases. No gaseous absorption is considered and the solar zenith angle is set to $0^{\circ}$. The ratios of direct to total downward solar radiation at the surface in the peak $0.7 \mu \mathrm{m}$ spectral range were computed for $19 \tau$ values $(0,0.05,0.1,0.15,0.2,0.25,0.3$, $0.35,0.4,0.45,0.5,0.55,0.6,0.7,0.8,0.9,1.0,1.2$, and 1.5) and were used as the $k$ values. To simplify the calculation, we assumed a solution at the VIIRS DNB peak wavelength. However, follow-up studies are needed to carefully evaluate $k$ values with the use of the actual sensor filter function and artificial light emission spectrum.

For the purpose of this concept of demonstration paper, we used a first-order approximation for obtaining $k$. That means we took the original $\tau$ value without the $k$ correction as input and interpolated between the 19 calculated $k$ values to find an approximate $k$ correction value for our input $\tau$. With this estimated $k$ value, we recalculated $\tau$ according to Eq. (7). This recalculation of $\tau$ was only performed once, and there was no iterative procedure; this was merely a first-order approximation. The purpose of not including an iterative process is because there are uncertainties in the final retrieved $\tau$. Therefore, an iterative process of matching $k$ to $\tau$ will introduce cumulated uncertainties in the final retrieved $\tau$.

\section{Assessment}

\subsection{Results}

Figure 4a shows the comparison between the $\tau$ derived from Eq. (7) and AERONET-derived $\tau$. Mean values of two bracketing AERONET observations (defined as the most recent daytime measurement from before the VIIRS nighttime overpass and the first measurement after the overpass the following day, so long as the two measurements are no more than $24 \mathrm{~h}$ apart) are used to represent the nighttime AERONET value. The error bars of the AERONET data represent the $\tau$ range between the two daytime AERONET values that are used for estimating the nighttime value. As seen in Table 2 and Fig. 4a, the coefficient of determination of the estimated nighttime AERONET $\tau$ and $\tau$ derived from Eq. (7) (with $k=$ 1) is 0.69 (RMSE of 0.14). However, a systematic low bias
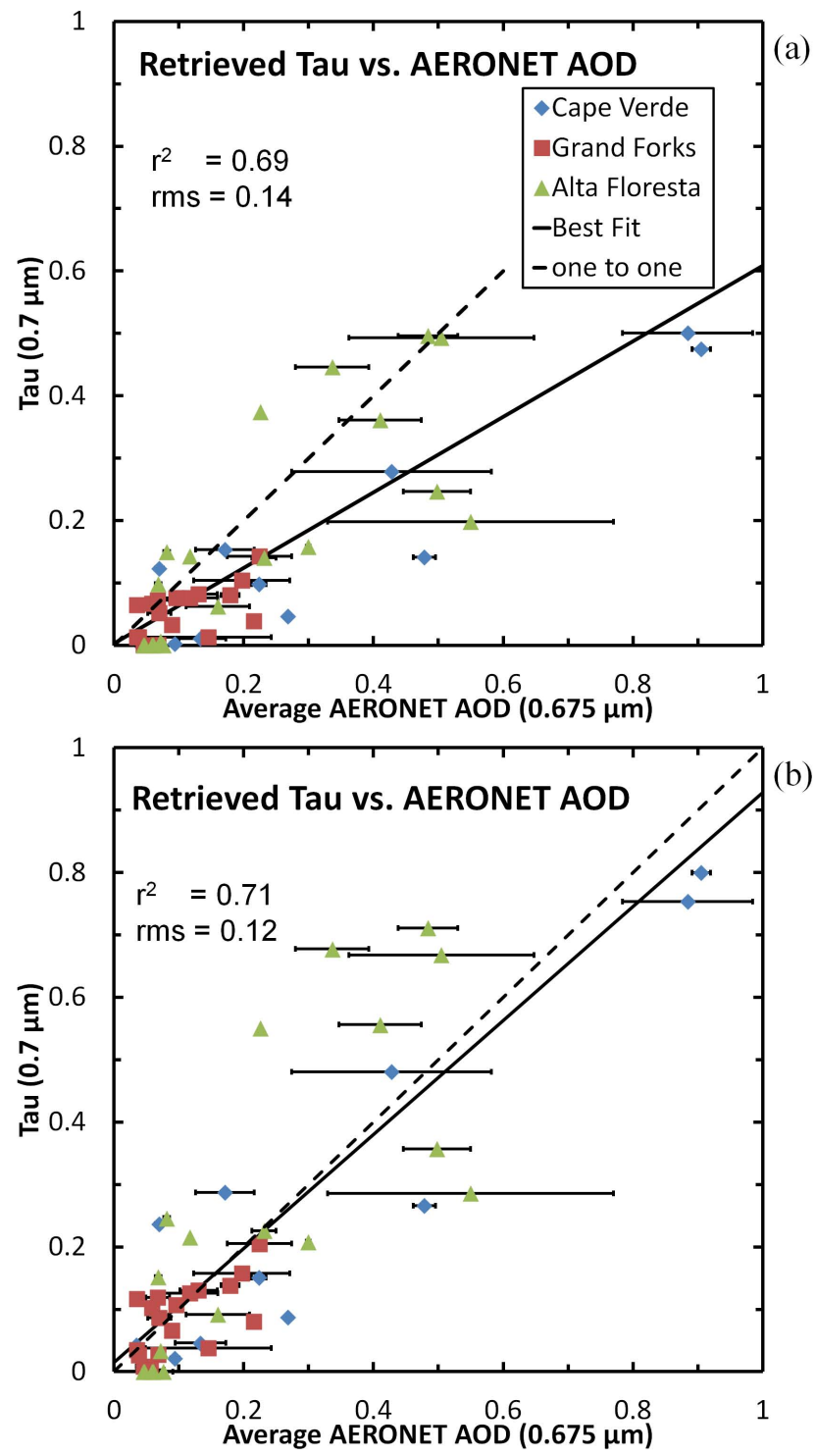

Fig. 4. (a) Scatter plot of estimated AERONET $\tau$ (approximated by the nearest daytime observations) versus VIIRS-retrieved $\tau$ ignoring the diffuse transmission of artificial light $(k=1)$, and (b) for $k$ estimated with the $6 \mathrm{~S}$ model using the urban aerosol model for Grand Forks, the desert aerosol model for Cape Verde, and the biomass burning aerosol model for Alta Floresta.

in the VIIRS-retrieved $\tau$ is also observed for the data from Cape Verde. The low bias is likely due to the upward diffuse transmission term in Eq. (7) that is not accounted for when $k$ is equal to 1 . Figure $4 \mathrm{~b}$ shows the same comparison with $k$ values calculated as mentioned previously, using the urban aerosol model for Grand Forks, the desert aerosol model for Cape Verde, and the biomass burning aerosol model for Alta Floresta. With the diffuse transmission term taken into account, the underestimation of $\tau$ improves and a closer to one-to-one relationship between AERONET and VIIRS $\tau$ is found. Table 2 shows the coefficient of determination, slope, 
Table 2. Coefficient of determination, slope, and RMSE values obtained by comparing the retrievals from Eq. (7) to average AERONET $\tau$ values taken from before and after the VIIRS satellite overpass. Results are shown for the case where no diffuse transmission correction is applied ( $k$ in Eq. 7 set to 1 ), and the case where the 6s urban aerosol model is used for Grand Forks, the desert model is used for Cape Verde, and the biomass burning model is used for Alta Floresta.

\begin{tabular}{lccc}
\hline & $\begin{array}{c}\text { Coefficient of } \\
\text { Determination }\end{array}$ & Slope & RMSE \\
\hline $\begin{array}{l}\text { Retrieved } \tau \text { (no diffuse } \\
\text { transmission correction) }\end{array}$ & 0.69 & 0.60 & 0.14 \\
\hline $\begin{array}{l}\text { Retrieved } \tau \text { (with diffuse } \\
\text { transmission correction) }\end{array}$ & 0.71 & 0.91 & 0.12 \\
\hline
\end{tabular}

and RMSE values for two cases: (1) the upward diffuse transmission term was not taken into account by setting $k$ to one, and (2) $k$ values were estimated using the desert aerosol model for Cape Verde, the urban aerosol model for Grand Forks, and the biomass burning aerosol model for Alta Floresta. Table 2 suggests that the retrieved $\tau$ is sensitive to the aerosol model used in the retrieval process.

Figure 4 suggests that Eq. (7) may be viable for estimating nighttime aerosol optical depth from VIIRS. However, a careful selection of target artificial light sources, and a careful study of $C, k$, and the stability of $I_{\mathrm{a}}$ are needed before applying the algorithm to a larger domain.

Figure 5 shows a time series of level 1.5 AERONET $\tau$ and the retrieved VIIRS nighttime $\tau$ based on Eq. (7). The retrieved nighttime $\tau$ values generally follow the AERONET $\tau$. At Grand Forks (Fig. 5a), VIIRS $\tau$ retrievals were less than zero for two nights, and these retrievals were set to zero. However, when the urban aerosol model was used to estimate $k$ values, these retrievals were both positive. Several negative retrievals at Alta Floresta (Fig. 5c) were also obtained and set to zero. These retrievals are likely due to the estimated value for $I_{\mathrm{a}}$. Correcting for the diffuse transmission of artificial light appears to improve the performance of the VIIRS-retrieved $\tau$ at Cape Verde (Fig. 5b), especially for high aerosol loading cases. At the beginning of the time series for Alta Floresta (Fig. 5c), the AERONET $\tau$ values are low, increasing to $0.4-0.5$ by the end of August and remaining at elevated levels into September. A similar pattern is also captured by the retrieved nighttime $\tau$ from VIIRS.

There are a few limitations in this study. First, in the derivation of Eq. (7), it was assumed that the quantity $r_{\mathrm{s}} \bar{r}$ is negligible. However, this assumption will begin to break down as the amount of aerosol in the atmospheric column increases. Thus, due to this assumption alone, one would expect that the proposed algorithm will perform worse for high $\tau$ cases without any further modifications. Compounding the problem of the $r_{\mathrm{s}} \bar{r}$ assumption is the fact that the signal-to-background ratio at Cape Verde is not particularly

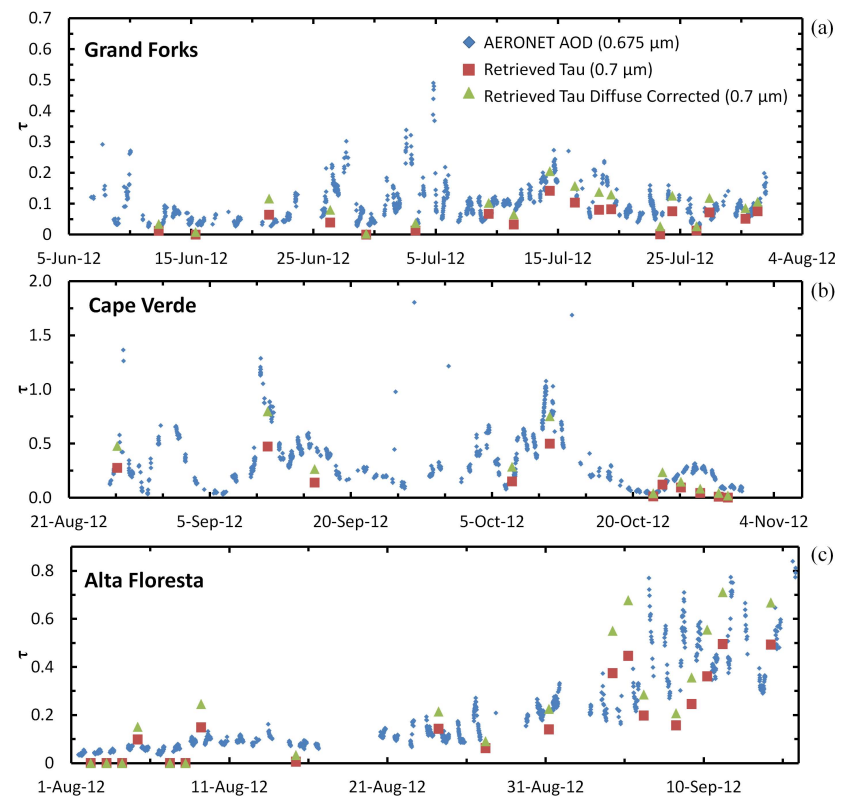

Fig. 5. (a) Time series for Grand Forks showing AERONET $\tau$, and VIIRS-retrieved $\tau$ ignoring the diffuse transmission of light $(k=1)$ and using the 6S urban aerosol model to estimate $k$. (b) Similar to Fig. 5a except for Cape Verde and using the $6 \mathrm{~S}$ desert aerosol model to estimate $k$. (c) Similar to Fig. 5a except for Alta Floresta and using the $6 \mathrm{~S}$ biomass burning aerosol model to estimate $k$.

strong, especially on nights with moonlight. The low signalto-background ratio at Cape Verde, especially on nights with high $\tau$, might introduce difficulty in obtaining an accurate signal for retrieving $\tau$. Thus, using cities with higher signalto-background ratios (brighter lights), such as Grand Forks, is more ideal. It should also be noted that the intensity of an artificial light source $\left(I_{\mathrm{a}}\right)$ may vary with respect to time of day, viewing geometry, season, and city growth. Therefore, any unaccounted increase in radiance at the detector will result in an underestimation of retrieved $\tau$. The variation of $I_{\mathrm{a}}$ will be explored in a future paper.

\subsection{Sensitivity of the retrieved process to $I_{\mathrm{a}}, C$, and $k$.}

Being important components of the retrieval process, it is necessary to estimate the sensitivity of the retrieval process to errors in $I_{\mathrm{a}}, C$, and $k$. The uncertainty in retrieved $\tau$ can be written by taking the total derivative of Eq. (7):

$\mathrm{d} \tau=\mu\left(\frac{\mathrm{d} I_{\mathrm{a}}}{I_{\mathrm{a}}}-\frac{\mathrm{d} \Delta I}{\Delta I}+\frac{\mathrm{d} C}{C}-\frac{\mathrm{d} k}{k}\right)$,

where $\Delta I$ is $I_{\text {sat }}-I^{\prime}$ sat. Each term on the right-hand side of Eq. (10) represents the relative error of a quantity composing $\tau$ in Eq. (7). For example, a $5 \%$ change in $C$, or $\mathrm{d} C / C=0.05$, introduces an uncertainty in the retrieved $\tau$ of $0.05 \mu$. This leads to an uncertainty in $\tau$ of 0.05 at nadir $(\mu=1)$ and 0.025 at a viewing angle of $60^{\circ}(\mu=0.5)$. The 
Table 3. Estimated values of uncertainty in retrieved $\tau$ due to $I_{\mathrm{a}}$, $\Delta I$ (the difference between $I_{\text {sat }}$ and $I^{\prime}$ sat $)$, and $k$.

\begin{tabular}{lrrr}
\hline & $\mathrm{d} I_{\mathrm{a}} / I_{\mathrm{a}}$ & $\mathrm{d} \Delta I / \Delta I$ & $\mathrm{~d} k / k$ \\
\hline $\begin{array}{l}\text { Average estimated } \\
\text { uncertainty in } \tau\end{array}$ & $0.02-0.04$ & $0.01-0.03$ & $0.04-0.1$ \\
\hline
\end{tabular}

uncertainty of retrieved $\tau$, based on Eq. (10), is not a direct function of $\tau$. Therefore, the larger $\tau$ is, the smaller the relative uncertainty of the retrieved $\tau$. A $5 \%$ change in $C$ at nadir introduces a $10 \%$ uncertainty for $\tau=0.5$ and a $5 \%$ uncertainty for $\tau=1$. The relative uncertainty in retrieved $\tau$ decreases as $\tau$ increases. The same is true regarding the satellite viewing angle; the relative uncertainty in $\tau$ decreases as the viewing angle increases. Based on Eq. (10), similar arguments also hold for $I_{\mathrm{a}}, \Delta I$, and $k$. It is interesting to note that the various components of uncertainty in Eq. (10) may partially cancel each other. For instance, increasing uncertainties in $C$ and $k$ will decrease the total uncertainty in $\tau$ so long as the uncertainties are either both positive or both negative.

Aside from the theoretical uncertainty analysis, a preliminary empirical uncertainty analysis was also conducted for $I^{\prime}$ sat (or $\Delta I$ by varying the background) and $I_{\mathrm{a}}$ as discussed in the previous sections. We have summarized the results of these average uncertainties in Table 3. In addition, we approximated $k$ using the desert, urban, and biomass burning aerosol models from the $6 \mathrm{~S}$ radiative transfer model for Cape Verde, Grand Forks, and Alta Floresta, respectively. We find an average relative change in $k(\Delta k / k)$ of approximately 0.1 between the smoke and dust aerosol models. An average $(\Delta k / k)$ of approximately 0.04 is found between the smoke and urban aerosol models. Such a change in $k$ values corresponds to a 0.04 to 0.1 uncertainty in $\tau$ based on Eq. (10). We have included the $\Delta k / k$ estimation in Table 3 as well.

Table 3 does not include an estimate for the uncertainty in $\tau$ due to the factor $C$ because the use of $C$ was not deemed to be necessary at Alta Floresta or Cape Verde from the results shown in Fig. 3. $C$ was used at Grand Forks; however, $C$ was also used to adjust the moonless night $I_{\text {sat }}$ values for extrapolating an estimated $I_{\mathrm{a}}$ value for determining the uncertainty in $\tau$ due to $I_{\mathrm{a}}$. Thus, for Grand Forks the uncertainty in $\tau$ due to $C$ is partially included in the uncertainty due to $I_{\mathrm{a}}$. An extensive number of observations are needed to carefully study the relationship between $I_{\mathrm{a}}$ and $C$, which might be unique to an individual city. We leave the full study of the interaction between $I_{\mathrm{a}}$ and $C$ to a future paper.

We want to remind the readers that both the theoretical and empirical uncertainty analyses in this section are rather simplified approaches. Uncertainties in aerosol properties $(k)$ and the true city signal $\left(I_{\mathrm{a}}\right)$ may vary as $\tau$ increases. For example, the wrong aerosol model may be chosen for the $k$ correction, which would have a greater impact with larger values of $\tau$ because $k$ may be a function of $\tau$. With regard to $I_{\mathrm{a}}$, a larger uncertainty may exist in estimating $I_{\mathrm{a}}$ for a region that is consistently covered with thick aerosol plumes than for a relatively clear region. Also, omitted terms such as $r_{\mathrm{s}} \bar{r}$ can become less insignificant as $\tau$ increases. Therefore, the actual performance of the retrieval process needs to be further evaluated using ground-based nighttime aerosol observations (e.g., Berkoff et al., 2011).

As alluded to earlier, Eq. (10) can also give us an estimate of the impact the VIIRS DNB stray-light issue will have on the retrieved $\tau$ values at Grand Forks. As noted in Sect. 3.3, the maximum impact of the stray-light issue would be on the same order of magnitude as the background values, which is an order of magnitude smaller than $I_{\mathrm{a}}$, or approximately $10 \%$. By Eq. (10) a $10 \%$ error in $I_{\mathrm{a}}$ will lead to a maximum uncertainty of 0.05 at a viewing angle of $60^{\circ}(\mu=0.5)$ and a maximum uncertainty of 0.1 at nadir.

\section{Conclusions and implications}

To demonstrate a new concept in this paper, a new method for retrieving nighttime $\tau$ using observations from the VIIRS DNB is presented. The new method is based on theoretical radiative transfer equations for the retrieval of aerosol optical depth using signal differences between areas with and without artificial light emissions. This study suggests the following:

1. The contrast between regions with and without artificial lights can be effectively used in retrieving aerosol optical depth, and this method deserves further evaluation as a potential operational satellite nighttime aerosol product.

2. The parameters $C$ and $I_{\mathrm{a}}$ are notable sources of uncertainty in the aerosol optical depth retrievals, and their sensitivity needs to be further evaluated in future studies. Also, determining the ratio of observed direct and total (direct + diffuse) artificial light energy, $k$, needs to be investigated for more accurate retrievals. Future work should include additional nighttime $\tau$ validation sources besides AERONET, such as CALIPSO.

3. Using artificial lights to obtain nighttime aerosol properties is feasible; however, the temporal and geometric variations of artificial light source intensity needs to be studied in order to apply this technique globally.

4. Cloud detection, especially thin cirrus cloud detection, is important to the proposed aerosol retrieval method. Alternatively, the method illustrated in this study for aerosol property retrievals can be directly applied to nighttime thin cloud optical depth retrievals.

5. Although not discussed in this paper, with the presence of aerosol plumes, the changes in TOA reflectance are clearly observable from the VIIRS DNB. This piece of 
information alone can be used to develop an aerosol product in a future study using similar approaches currently implemented in the daytime algorithms (e.g., Remer et al., 2005), taking advantage of a lunar model tailored to the VIIRS DNB (e.g., Miller and Turner, 2009).

Acknowledgements. This research was funded by the Office of Naval Research Code 32 and the UND seed money grant. Author S. D. M. acknowledges the support of the Naval Research Laboratory through contract N00173-10-C-2003. The group acknowledges the AERONET program, their contributing principal investigators, and their staff for coordinating the sites used in this investigation.

Edited by: O. Torres

\section{References}

Benedetti, A., Morcrette, J.-J., Boucher, O., Dethof, A., Engelen, R. J., Fisher, M., Flentje, H., Huneeus, N., Jones, L., Kaiser, J. W., Kinne, S., Mangold, A., Razinger, M., Simmons, A. J., and Suttie, M.: Aerosol analysis and forecast in the European Centre for Medium-Range Weather Forecasts Integrated Forecast System: 2. Data assimilation, J. Geophys. Res., 114, D13205, doi:10.1029/2008JD011115, 2009.

Berkoff, T. A., Sorokin, M., Stone, T., Eck, T. F., Raymond Hoff, R., Welton, E., and Holben, B.: Nocturnal Aerosol Optical Depth Measurements with a Small-Aperture Automated Photometer Using the Moon as a Light Source, J. Atmos. Ocean. Technol., 28, 1297-1306, 2011.

Campbell, J. R., Reid, J. S., Westphal, D. L., Zhang, J., Hyer, E. J., and Welton, E. J.: CALIOP aerosol subset processing for global aerosol transport model data assimilation, J. Sel. Top. Appl. Earth Obs. Remote Sens., 3, 203-214, doi:10.1109/JSTARS.2010.2044868, 2010.

Campbell, J. R., Tackett, J. L., Reid, J. S., Zhang, J., Curtis, C. A., Hyer, E. J., Sessions, W. R., Westphal, D. L., Prospero, J. M., Welton, E. J., Omar, A. H., Vaughan, M. A., and Winker, D. M.: Evaluating nighttime CALIOP $0.532 \mu \mathrm{m}$ aerosol optical depth and extinction coefficient retrievals, Atmos. Meas. Tech., 5, 2143-2160, doi:10.5194/amt-5-2143-2012, 2012.

Elvidge, C. D., Baugh, K. E., Dietz, J. B., Bland, T., Sutton, P. C., and Kroehl, H. W.: Radiance calibration of DMSP-OLS lowlight imaging data of human settlements, Remote Sens. Environ., 68, 77-88, 1999.

Elvidge, C. D., Imhoff, M. L., Baugh, K. E., Hobson, V. R., Nelson, I., Safran, J., Dietz, J. B., and Tuttle, B. T.: Night-time lights of the world: 1994-1995, ISPRS J. Photogramm., 56, 81-99, 2001.

Holben, B. N., Eck, T. F., Slutsker, I., Tanré, D., Buis, J. P., Setzer, A., Vermote, E., Reagan, J. A., Kaufman, Y. J., Nakajima, T., Lavenu, F., Jankowiak, I., and Smirnov, A.: AERONET - A Federated Instrument Network and Data Archive for Aerosol Characterization, Remote Sens. Environ., 66, 1-16, 1998.

Kaufman, Y. J., Tanre, D., and Boucher, O.: A satellite view of aerosols in the climate system, Nature, 419, 215-223, 2002.

Lanciano, O. and Fiocco, G.: Nighttime measurements of atmosphere optical thickness by star photometry with a digital camera, Appl. Opt., 46, 5176-5182, 2007.
Lee, S. and Sohn, B. J.: Nighttime AOT Retrieval for Asian Dusts from MODIS IR Measurements: An Artificial Neural Network Approach, J. Meteorol. Soc. Jpn., 90, 163-177, doi:10.2151/jmsj.2012-201, 2012.

Lee, T. F., Miller, S. D., Schueler, C., and Miller, S.: NASA MODIS previews NPOESS VIIRS capabilities, Weather Forecast., 21, 649-655, 2006.

Miller, S. D. and Turner, R. E.: A dynamic lunar spectral irradiance dataset for NPOESS/VIIRS Day/Night Band nighttime environmental applications, IEEE Trans. Geosci. Remote Sens., 47, 2316-2329, doi:10.1109/TGRS.2009.2012696, 2009.

Reid, J. S., Benedetti, A., Colarco, P. R., and Hansen, J. A.: International operational aerosol observability workshop, B. Am. Meteorol. Soc., 92, ES21-ES24, doi:10.1175/2010BAMS3183.1, 2011.

Remer, L. A. and Kaufman, Y. J.: Dynamic aerosol model: Urban/industrial aerosol, J. Geophys. Res., 103, 13859-13871, doi:10.1029/98JD00994, 1998.

Remer, L. A., Kaufman, Y. J., Tanré, D., Mattoo, S., Chu, D. A., Martins, J. V., Li, R.-R., Ichoku, C., Levy, R. C., Kleidman, R. G., Ecd, T. F., Vermote, E., and Holben, B. N.: The MODIS aerosol algorithm, products, and validation, J. Atmos. Sci., 62, 947-973, 2005.

Schmid, B., Michalsky, J., Halthore, R., Beauharnois, M., Harrison, L., Livingston, J., Russell, P., Holben, B., Eck, T., and Smirnov, A.: Comparison of aerosol optical depth from four solar radiometers during the Fall 1997 ARM intensive observation period, Geophys. Res. Lett., 26, 2725-2728, 1999.

Sekiyama, T. T., Tanaka, T. Y., Shimizu, A., and Miyoshi, T.: Data assimilation of CALIPSO aerosol observations, Atmos. Chem. Phys., 10, 39-49, doi:10.5194/acp-10-39-2010, 2010.

Vermote, E. F., Tanré, D., Deuzé, J. L., Herman, M., and Morcrette, J. J.: Second simulation of the satellite signal in the solar spectrum, 6S: an overview, IEEE Trans. Geosci. Remote Sens., 35, 675-686, 1997.

Vincent D. A., Durkee, P. A., Nielsen, K. E., Zhang, J., and Reid, J. S.: Aerosol optical depth retrievals from high-resolution commercial satellite imagery over areas of high surface reflectance, 14th Conference on Satellite Meteorology and Oceanography, Atlanta, GA, 2006.

Winker, D. M., Vaughan, M. A., Omar, A., Hu, Y., Powell, K. A., Liu, Z., Hunt, W. H., and Young, S. A.: Overview of the CALIPSO Mission and CALIOP Data Processing Algorithms, J. Atmos. Ocean. Technol., 26, 2310-2323, 2009.

Zhang, J. and Christopher, S. A.: "Longwave radiative forcing of Saharan dust aerosols estimated from MODIS, MISR, and CERES observations on Terra, Geophys. Res. Lett., 30, 2188, doi:10.1029/2003GL018479, 2003.

Zhang, J., Christopher, S. A., Remer, L. A., and Kaufman, Y. J.: Shortwave aerosol radiative forcing over cloud-free oceans from Terra: 1. Angular models for aerosols, J. Geophys. Res., 110, D10S23, doi:10.1029/2004JD005008, 2005a.

Zhang, J., Christopher, S. A., Remer, L. A., and Kaufman, Y. J. Shortwave aerosol radiative forcing over cloud-free oceans from Terra: 2. Seasonal and global distributions, J. Geophys. Res., 110, D10S24, doi:10.1029/2004JD005009, 2005b.

Zhang, J., Reid, J. S., Westphal, D. L., Baker, N. L., and Hyer, E. J.: A system for operational aerosol optical depth data assimilation over global oceans, J. Geophys. Res., 113, D10208, 
doi:10.1029/2007JD009065, 2008a.

Zhang, J., Reid, J. S., Turk, J., and Miller, S.: Strategy for studying nocturnal aerosol optical depth using artificial lights, Int. J. Remote Sens., 29, 4599-4613, 2008b.
Zhang, J., Campbell, J. R., Reid, J. S., Westphal, D. L., Baker, N. L., Campbell, W. F., and Hyer, E. J.: Evaluating the impact of assimilating CALIOP-derived aerosol extinction profiles on a global mass transport model, Geophys. Res. Lett., 38, L14801, doi:10.1029/2011GL047737, 2011. 